\title{
Menumbuhkan Motivasi Warga Belajar Melalui Media Audio- Visual di SKB
}

\author{
A.Ismail Lukman ${ }^{1}$ \\ ${ }^{1}$ Prodi Pendidikan Masyarakat, Universitas Mulawarman, Indonesia
}

*Corresponding author: a.ismail.lukman@gmail.com

\begin{abstract}
Abstrak
Pengabdian ini bertujuan untuk menumbuhkan motivasi warga belajar melalui media audio-visual. Pengabdian memaparkan mengenai peran media audio-visual dalam menciptakan suasana belajar yang menyenangkan, tidak kaku, dan tidak membosankan. Pelaksanaan pengabdian dilakukan dengan beberapa tahapan, yaitu 1) persiapan, berupa pengurusan izin dan penentuan waktu pelaksanaan kegiatan; 2) pelaksanaan kegiatan pengabdian kepada masyarakat atau penyuluhan. Dengan susunan kegiatan. a) Sambutan sekaligus pembukaan oleh anggota penguluhan yang bertindak sebagai moderator. b) Pemaparan materi. Materi mengenai media audio-visual dipaparkan oleh narasumber, tanya jawab dengan peserta, dan simulasi kegiatan pembelajaran dengan menggunakan media audio-visual berupa pembelajaran keaksaraan menggunakan lagu aksara. c) Penutup. Narasumber kemudian memberikan arahan, pesan-pesan, motivasi, dan harapan kepada peserta penyuluhan untuk terus belajar, dan tidak cepat merasa puas dengan apa yang telah dipelajari selama ini. 3) Evaluasi. Evaluasi dilihat dari ketercapaian kegiatan penyuluhan. Indikatornya, warga belajar menjadi termotivasi untuk ikut dalam program pendidikan. Selain itu, peserta terlihat nyaman, senang, dan tidak bosan dalam mengikuti pembelajaran.
\end{abstract}

Kata Kunci: Motivasi, Media Audio Visual, Sanggar Kegiatan Belajar (SKB)

\section{Abstract}

This service aims to foster the motivation of citizens to learn through audio-visual media. Devotion describes the role of audio-visual media in creating a learning atmosphere that is fun, not stiff, and not boring. The implementation of the service is carried out in several stages, namely 1) preparation, in the form of obtaining permits and determining the time for the implementation of activities; 2) implementation of community service activities or counseling. With a schedule of activities. a) Welcoming and opening remarks by the counseling member who acts as a moderator. b) Presentation of the material. Materials regarding audio-visual media were presented by resource persons, asked questions with participants, and simulated learning activities using audiovisual media in the form of literacy learning using script songs. c) Cover. The resource person then gave directions, messages, motivation, and hope to the counseling participants to continue learning, and not to be quickly satisfied with what they had learned so far. 3) Evaluation. Evaluation is seen from the achievement of outreach activities. The indicator is that learning residents are motivated to participate in educational programs. In addition, the participants looked comfortable, happy, and not bored in participating in the lesson.

Keywords: Motivation, Audio Visual Media, Learning Activity Studio (LAS)

\section{INTRODUCTION}

Pendidikan adalah salah satu gerbang menuju keberhasilan sebuah Negara. Pendidikan merupakan sebuah proses memanusiakan manusiakan, menjadikan manusia yang sesaui dengan tujuan pendidikan. Pendidikan yang berkualitas akan menghasilkan SDM yang berkualitas. Pendidikan tidak terlepas dari proses pembelajaran. Pembelajaran merupakan salah satu aspek yang memegang peranan penting dalam proses pengelolaan pendidikan(Sarifudin, 2019). Proses pembelajaran untuk mengembangkan atau meningkatkan kemampuan tertentu sehingga sasaran pendidikan itu dapat berdiri sendiri (Suryani \& Kholidya, 2020; Tambunan \& Nainggolan, 2013). Pembelajaran adalah proses interaksi yang baik antara peserta didik dengan sumber belajar. Suatu proses pembelajaran dapat berjalan dengan baik atau tidak, dapat dilihat dari tercapai atau tidaknya tujuan pembelajaran yang

$\begin{array}{ll}\text { History: } & \\ \text { Received } & \text { : August 01, } 2021 \\ \text { Revised } & \text { : August 02, } 2021 \\ \text { Accepted } & \text { : August 20, } 2021 \\ \text { Published } & \text { : August 25, } 2021\end{array}$


ditetapkan (Poerwanti \& Winarni, 2021). Keberhasilan proses pembelajaran dipengaruhi oleh beberapa factor. Salah satu factor yang mendukung proses pembelajaran adalah motivasi. Motivasi merupakan kegiatan yang mengakibatkan, menyalurkan, memelihara dan mendorong perilaku manusia (Yuangga \& Manik, 2018). Motivasi adalah usaha yang didasari untuk mengerahkan dan menjaga tingkah seseorang agar ia terdorong untuk bertindak melakukan sesuatu, sehingga mencapai hasil atau tujuan tertentu (Alannasir, 2016). Motivasi akan berpengaruh pada usaha seseorang, ketekunan seseorang, serta berpengaruh dalam menentukan penyelesaian terhadap hambatan yang dihadapi oleh seseorang dalam menyelesaikan masalah (Siswati et al., 2017). Motivasi adalah suatu dorongan dari dalam diri dan luar diri individu yang menyebabkan individu bergerak untuk melakukan suatu hal dalam mencapai hasrat dan tujuan tertentu (Zulfa et al., 2017). Jadi, motivasi adalah salah satu factor yang penting dalam proses pembelajaran. Pentingnya motivasi menuntut pendidik untuk menciptakan pembelajaran yang mambuat peserta didik untuk mempunyai motivasi tinggi. Namun, kegiatan pembelajaran tidak selalu berjalan mulus, terkadang terdapat permasalahan dalam pelaksanaannya. Permasalahan yang dapat terjadi yaitu (1) Ketidakmampuan secara ekonomi menjadi sebab warga belajar tidak mengenyam pendidikan formal sehingga warga belajar mengalami putus sekolah, (2) Kurangnya motivasi masyarakat atau warga belajar untuk mengikuti pembelajar sehingga berakibat pada seringnya masyarakat meninggalkan lokasi pembelajaran, (3) Pembelajaran bersifat kaku dan kurang dapat mentransfer materi- materi pengajaran sehingga berdampak pada kurangnya kemampuan warga belajar dalam memahami materi, (4) Seringnya timbul rasa bosan dan keinginan untuk tidak melanjutkan proses kegiatan pembelajaran pada warga belajar, (5) Kurangnya informasi atau kreativitas dari tutor untuk menciptakan proses pembelajaran yang menyenangkan.

Cara yang dapat menjaga atau menimbulkan motivasi warga belajar untuk ikut dalam proses pendidikan atau pembelajaran adalah cara guru dalam menyampaikan materi pembelajaran. Guru (tutor) dituntut kreatif agar dapat membangkitkan motivasi belajar (Nurhalim, 2016; Suprihatin, 2015). Salah satu bagian pembelajaran yang harus diperhatikan oleh tutur adalah media yang digunakan. Media yang dimaksud adalah media audio visual. Tutor dapat memodifikasi media dalam berbagai bentuk sesuai dengan kebutuhan warga belajar untuk menciptakan suasana yang menyenangkan, dapat menarik perhatian warga belajar, dan terutama dapat memudahkan warga belajar. Media akan mampu menimbulkan rasa menyenangkan sehingga warga belajar merasa tidak bosan dan mudah dalam belajar. Media Audio Visual dapat menambah efektivitas komunikasi dan interaksi antara tutor dan warga belajar. Media audio visual adalah media yang mampu merangsang indera penglihatan dan indra pendengaran secara bersama-sama, karena media ini mempunyai unsur suara dan unsur gambar (Firdaus et al., 2018; Nomleni \& Manu, 2018). Media Audio-visual dapat menumbuhkan motivasi belajar (Ibrahim, 2019; Pranowo \& Prihastanti, 2020). Penggunaan media harus sejalan dengan tujuan pengajaran yang telah dirumuskan. Media pembelajaran audio-visual adalah media yang membawa pesan-pesan atau informasi yang bertujuan instruksional atau mengandung maksud-maksud pengajaran. Pembelajaran yang terkesan kaku dirasakan menjadi sebab utama rendahnya kualitas pembelajaran. Hadirnya media audio-visual sebagai wujud pengembangan dari media pembelajaran berkontribusi besar dalam proses pembelajaran. Media audio-visual yang digunakan dapat dimodifikasi berupa gambar, video, cerita, atau lagu. Salah satu mitra yang mengalami masalah dengan proses pembelajaran berkaitan dengan rendahnya motivasi adalah Sangar kegiatan Belajar (SKB).

Sanggar Kegiatan Belajar (SKB) merupakan salah satu wadah pendidikan nonformal (Pamungkas \& Nugroho, 2021; Riswandi, 2018). SKB merupakan lembaga yang mempunyai tugas fungsi mengembangkan program-program pendidikan luar sekolah (pendidikan nonformal) (Widodo, 2017). Pendidikan nonformal memiliki karakteristik diantaranya adalah efisiensi waktu (Widodo \& Nusantara, 2020). Sanggar Kegiatan Belajar (SKB) Samarinda. 
Pemilihan lokasi kegiatan karena berdasar pada berbagi pertimbangan salah satunya adalah SKB Samarinda memiliki berbagai kegiatan atau program yang berarti bahwa jumlah warga belajarnya juga banyak. Sebab, ketidaktahuan atau ketidakmampuan warga belajar akan berdampak panjang pada masa depan, terutama warga belajar yang masih anak-anak. Salah satu solusi yang bisa ditawarkan untuk mengatasi masalah ini adalah dengan kegiatan penyuluhan. Kegiatan penyuluhan merupakan salah satu kegiatan yang dianggap penting dan mampu untuk memberikan penyadaran kepada pihak-pihak yang terlibat dalam pembelajaran, dalam hal ini tutor dan warga belajar. Kegitan penyuluhan bisa memberikan pengetahuan dan keterampilan kepada mitra (Budaraga et al., 2019). Tujuan dari penyuluhan untuk meningkatkan motivasi warga belajar untuk mengikuti proses pembelajaran yang menyenangkan sehingga warga belajar terdorong dan intens untuk melakukan pertemuan pembelajaran. Kegiatan penyuluhan juga dapat mengubah pola pikir warga belajar untuk tidak merasa tertinggal karena tidak mampu atau baru memulai pendidikan.

\section{MATERIALS AND METHODS}

Metode mengabdian sekaitan dengan kegiatan penyuluhan untuk meningkatkan motivasi warga belajar melalui media audio visual terdiri atas beberapa tahapan yang dilakukan: 1) Persiapan. Persiapan yang dilakukan terencana agar hasil yang diperoleh sesuai dengan apa yang diharapkan. Adapun tahap persiapan yang dilakukan, yaitu: a) mempersiapkan kelegalan kegiatan, termasuk persuratan atau perizinan untuk melakukan kegiatan penyuluhan yang ditunjukan kepada beberapa instansi terkait, terutama pada SKB Samarinda sebagai lokasi kegiatan; b) memastikan peserta kegiatan siap untuk mengikuti kegiatan penyuluhan karena yang menjadi perserta penyuluhan adalah warga belajar, tutuor, dan penyelenggara; c) menjajaki lokasi kegiatan dan peserta penyuluhan agar kegiatan dapat berjalan dengan baik dan hasil kegiatan juga maksimal. d) mematangkan konsep kegiatan, termasuk memastikan pemateri yang menjadi pembicara sudah pasti dan mengetahui tema kegiatan. 2) Pelaksanaan. Pelaksanaan kegiatan dilakukan dengan beberapa langkah kegiatan. Adapun tahapan pelaksanaan kegiatan, yaitu: a) pembukaan dan pengenalan dengan peserta; b) sambutan dari berbagai pihak, sekaligus penyampaian maksud dan tujuan pelaksanaan kegiatan; c) pemaparan materi untuk meningkatkan motivasi peserta dalam hal ini warga belajar untuk mengikuti proses pembelajaran; d) tanya jawab interaktif dengan peserta; e) simulasi kegiatan pembelajaran dengan menggunakan media Audio visual dalam hal ini lagu aksara dan video untuk menciptakan situasi menyenangkan dalam proses pembelajaran; f) memberikan penguatan kepada peserta dalam hal ini warga belajar untuk tetap semangat belajar. 3) Evaluasi. Evaluasi menjadi tahap akhir dari kegiatan penyuluhan. Evaluasi dilihat dari ketercapaian kegiatan penyuluhan. Indikatornya, peserta penyuluhan dalam hal ini warga belajar menjadi termotivasi untuk ikut dalam program pendidikan. Bukan hanya itu, dari simulasi, peserta terlihat nyaman, senang, dan tidak bosan dalam mengikuti pembelajaran. Lokasi kegiatan pengabdian pada masyarakat yaitu kegiatan penyuluhan bagi warga belajar SKB Samarinda Provinsi Kalimantan Timur. Peserta kegiatan pengabdian masyarakat adalah peserta dalam hal ini warga belajar SKB Samarinda Provinsi Kalimantan Timur.

\section{RESULTS AND DISCUSSION}

Permohonan izin dan penentuan waktu pelaksanaan dilakukan kesepakatan atanra penyelenggara SKB dan Tim Pengabdi. Dalam pembicaraan dan diskusi tersebut, kami menyepakati waktu kegiatan, akan tetapi penyelenggara SKB menginformasikan terlebih dahulu kegiatan yang akan dilakukan tersebut kepada warga belajarnya yang nantinya akan 
menjadi peserta penyuluhan. Kami menyepakati untuk melaksanakan kegiatan penyuluhan pada malam hari. Pemilihan waktu malam hari dengan pertimbangan agar warga belajar yang hadir jumlahnya dapat lebih banyak. Sebab, warga belajar umumnya memiliki kegiatan pada siang hari dan agak sulit untuk dikumpulkan. Pelaksanaan kegiatan pengabdian terdiri atas tiga tahapan. Pertama. Pembukaan. Acara Pembukaan langsung dilakukan oleh kami selaku pelaksana kegiatan penyuluhan karena penyelenggara SKB berhalangan untuk hadir pada kegiatan tersebut. Sambutan dari anggota penyuluh yang bertindak sebagai moderator membuka kegiatan penyuluhan pada malam tersebut. Moderator juga memaparkan tujuan kegiatan penyuluhan dan memberikan pengantar mengenai materi yang akan disampaikan oleh ketua penyuluh. Dari hal tersebut, peserta penyuluhan antusias mendengarkan sehingga besar harapan kami melihat kegiatan pembukaan yang disambut dengan baik oleh peserta. Kedua. Pemaparan Materi. Ketua penyuluhan yang bertindak sebagai narasumber memberikan pengantar terlebih dahulu kepada peserta, memperkenalkan diri, dan mengulas kembali tujuan diadakannya penyuluhan sebelum memasuki materi ini. Narasumber kemudian memaparkan materi mengenai media audio visual yang disambut dengan baik dan penuh antusias oleh peserta penyuluhan. Peserta penyuluhan terlihat memperhatikan dengan saksama setiap penyempaian materi yang dibawakan oleh narasumber. Setelah selesai memaparkan materi, narasumber membuka sesi tanya jawab kepada peserta. Peserta dipersilakan untuk bertanya mengenai berbagai hal yang terkait dengan materi dan diberikan pula kesempatan untuk menanyakan hal lainnya. Pada sesi tersebut, terdapat beberapa peserta yang bertanya dengan penuh penasaran akan materi. Dari beberapa pertanyaan peserta, terlihat rasa penasaran dan dapat disimpulkan bahwa peserta dalam pembelajaran memerulakan sesekali media pembelajaran agar tercipta proses pembelajaran yang menyenangkan, tidak kaku, tidak membosankan, menarik perhatian peserta dalam hal ini warga belajar, dan membantu peserta dalam memahami dengan mudah materi.

Setelah proses tanya jawab yang interaktif dengan peserta, narasumber kemudian memberikan simulasi untuk pembelajaran dengan menggunakan media audio visual. Media audio visual perantara atau pengantar pesan dari pengirim kepada penerima pesan dengan menggunakan mesin-mesin mekanis dan elektronik untuk menyajikan pesan-pesan audio dan visual Arsyad (2011). Lebih lanjut, Munadi (2013) mengatakan bahwa media tersebut melibatkan indera pengelihatan dan pendengaran sekaligus dalam satu proses. Simulasi tersebut dengan pembelajaran keaksaraan menggunakan "lagu aksara" yang ditampilkan. Lagu aksara tersebut merupakan perpaduan antara lagu dan gambar sehingga menarik perhatian peserta. Tahap lanjut dari pelaksanaan mengarah pada isi model yang memiliki 5 alur secara berurutan sebagai contoh dalam penerapan media audio visual dalam pembelajaran. 1) Pengantar (introduction) merupakan bagian awal sebagai bentuk pengenalan dan pembuka pembelajaran menggunakan media "lagu aksara". Peserta diberikan arahan selama 10 menit untuk memahami dan dapat melaksanakan pembelajaran sesuai alur pembelajaran dengan media "lagu aksara". 2) Penayangan (performance) "lagu aksara" menggunakan alat yang meliputi proyektor dan gitar selama 15 menit. Penayangan "lagu aksara" dilakukan oleh narasumber sebagai operator dalam menyampaikan materi dalam bentuk nyanyian. Proyektor berfungsi sebagai alat untuk menayangkan materi keaksaraan yang berbentuk lirik lagu dan gitar berfungsi sebagai alat musik untuk mengiringi lagu (perpaduan suara dan gambar). 3) Latihan (practice), peserta mendapat panduan dari narasumber untuk mempraktikkan materi keaksaraan yang sudah ditayangkan dengan alokasi waktu 25 menit. 4) Uji kemampuan (test performance), peserta setelah melampaui tahap 1-3 kemudian diuji melalui tes yang berbentuk uji kemampuan. 5) Tinjauan (review) merupakan bentuk evaluasi formatif untuk melihat kembali tingkat kemampuan warga belajar setelah menggunakan media "lagu aksara" dalam pembelajaran keaksaraan dengan alokasi waktu 10 menit. Tahap terakhir, evaluasi untuk mengetahui tingkat ketercapaian pembelajaran keaksaraan menggunakan media "lagu aksara". 
Ketercapaian tersebut berupa peningkatan kemampuan. Ketiga. Penutup. Sehubungan dengan selesainya rangkaian kegiatan dan pemaparan materi dari narasumber, narasumber kemudian memberikan arahan, pesan-pesan, motivasi, dan harapan kepada peserta penyuluhan untuk terus belajar, dan tidak cepat merasa puas dengan apa yang telah dipelajari selama ini. Motivasi belajar peserta penyuluhan harus tetap dijaga dan dipupuk agar dapat mengubah hidup dan kehidupannya.

Berdasarkan hasil kegiatan penyuluhan yang dilakukan Warga belajar akan merasa senang dengan penggunaan media atau modifikasi media pembelajaran yang dapat mengusir rasa bosan warga belajar. Media dapat membantu warga belajar atau memudahkan warga belajar dalam memahami materi pembelajaran. Hal ini tentunya tidak terlepas dari kegiatan yang dilakukan dimana dengan adanya penyuluhan akan memberikan pengetahuan dan keterampilan kepada warga belajar (Budaraga et al., 2019). Penyuluhan yang sangat penting, karena memberikan kesempatan untuk mempengruhi perilaku masyarakat (Arafah, 2017). Penyuluhan merupakan pendidikan nonformal bagi petani beserta keluarganya, dimana kegiatan dalam ahli pengetahuan dan keterampilan dari penyuluh dan berlansung melalui dalam proses belajar mengajar (Allen et al., 2015; Diyah \& Setiawati, 2019). Jadi dengan adanya penyuluhan akan memberikan dampak yang positif terhadap warga belajar. Proses penyuluhan yang dilakukan berlangsung sangat menyenangkan karena warga belajar dikenalkan dengan media audio visual yang membuat proses belajaran dapat meningkatkan motivasi. Motivasi merupakan kegiatan yang mengakibatkan, menyalurkan, memelihara dan mendorong perilaku manusia (Yuangga \& Manik, 2018). Motivasi adalah usaha yang didasari untuk mengerahkan dan menjaga tingkah seseorang agar ia terdorong untuk bertindak melakukan sesuatu, sehingga mencapai hasil atau tujuan tertentu (Alannasir, 2016). Motivasi akan berpengaruh pada usaha seseorang, ketekunan seseorang, serta berpengaruh dalam menentukan penyelesaian terhadap hambatan yang dihadapi oleh seseorang dalam menyelesaikan masalah (Siswati et al., 2017). Motivasi adalah suatu dorongan dari dalam diri dan luar diri individu yang menyebabkan individu bergerak untuk melakukan suatu hal dalam mencapai hasrat dan tujuan tertentu (Zulfa et al., 2017). Jadi, motivasi adalah salah satu factor yang penting dalam proses pembelajaran

\section{CONCLUSION}

Peserta penyuluhan antusias dan tertarik mengikuti kegiatan penyuluhan. Hal tersebut terlihat dari keseriusan warga belajar mendengarkan materi, keaktifan warga belajar dalam bertanya, dan juga ketertarikan warga belajar mendengarkan materi. Materi penyuluhan sebagai gambaran kepada tutor dalam menciptakan suasana yang menyenangkan dan tidak kaku sehingga warga timbul motivasi dalam diri warga belajar untuk terus ikut dalam proses pembelajaran..Motivasi intrinsik dan motivasi ekstrinsi merupakan dua hal yang berkaitan dalam diri warga belajar. Kedua motivasi tersebut dapat saling mendukung. Dalam hal ini, media pembelajaran menjadi motivasi ekstrinsik untuk warga belajar yang dapat membantu menumbuhkan motivasi intrinsik. Warga belajar yang merasa senang mengikuti pembelajaran akan tumbuh dalam dirinya motivasi atau semangat untuk terus mengikuti proses pembelajaran tersebut.

\section{REFERENCES}

Alannasir, W. (2016). Pengaruh Penggunaan Media Animasi Dalam Pembelajaran Ips Terhadap Motivasi Belajar Siswa Kelas Iv Sd Negeri Mannuruki. Journal of Educational Science and Technology (EST), 2(2), 81. https://doi.org/10.26858/est.v2i2.2561. 
Allen, H. F., Batubara, M. M., \& Iswarini, H. (2015). Kendala Penyuluhan Dalam Melaksanakan Aktivitas Penyuluhan Pada Usahatani Kopi Di Kecamatan Dempo Utara Kota Pagar Alam. Societa, 4(2), 105-110. https://jurnal.umpalembang.ac.id/societa/article/download/242/214.

Arafah, F. N. (2017). Pelaksanaan Program Penyuluhan Perintisan Pusat Kegiatan Belajar Masyarakat (Pkbm) Di Lembaga Pemberdayaan Masyarakat (Lpm) Kelurahan Cihaurgeulis Kota Bandung. Jurnal Pendidikan Luar Sekolah, 13(1), 13-22. https://ejournal.upi.edu/index.php/pls/article/viewFile/8722/5412.

Budaraga, I. K., Ramaiyulis, R., Nurdin, E., \& Rauf, R. (2019). Penyuluhan Jajanan, Makanan dan Kantin Sehat di Sekolah SMA 2 Batang Anai Kecamatan Batang Anai Kabupaten Padang Pariaman. Buletin Udayana Mengabdi, 18(3), 61-67. https://doi.org/10.24843/bum.2019.v18.i03.p11.

Diyah, T. L., \& Setiawati. (2019). Pelaksanaan Penyuluhan Pertanian Menurut Kelompok Tani Korong Sungai Kalu Nagari Kudu Ganting Barat Kecamatan V Koto Timur Kabupaten Padang Pariaman. Jurnal of Multidiciplinary Reswach and Development, 1(2), 323331. https://jurnal.ranahresearch.com/index.php/R2J/article/view/58.

Firdaus, H., Sugiyono, \& Purnama, S. K. (2018). The Development Model of Badminton Base Technique Training Based of Audio Visual Media for The Beginner Athlete. Jurnal Pendidikan: Teori, Penelitian, Dan Pengembangan, 3(2), 210-214. https://doi.org/10.17977/jptpp.v3i2.10734.

Ibrahim, M. (2019). Pemanfaatan Media Audio Visual Dalam Meningkatkan Motivasi Belajar $\begin{array}{lllll}\text { Peserta Didik Paket } & \text { C. }\end{array}$ https://doi.org/10.17509/edusentris.v5i1.291.

Nomleni, F. T., \& Manu, T. S. N. (2018). Pengembangan Media Audio Visual dan Alat Peraga dalam Meningkatkan Pemahaman Konsep dan Pemecahan Masalah. Scholaria: Jurnal Pendidikan Dan Kebudayaan, 8(3), 219-230. https://doi.org/10.24246/j.js.2018.v8.i3.p219-230.

Nurhalim, A. K. B. K. (2016). Pengaruh Motivasi Belajar Terhadap Prestasi Belajar Warga Belajar Kejar Paket C. Journal of Nonformal Education and Community Empowerment, 5(1), 9-15. https://doi.org/10.15294/jne.v2i2.6789.

Pamungkas, T. L. J., \& Nugroho, R. (2021). Motivasi Belajar Peserta Didik Terhadap Pembelajaran Daring pada Program Pendidikan Kesetaraan Paket B di UPT SKB Cerme Gresik. Jurnal Pendidikan Untuk Semua, 5(1), 24-37. https://journal.unesa.ac.id/index.php/jpls/article/view/13531.

Poerwanti, J. I. S., \& Winarni, R. (2021). Pelatihan Dan Pendampingan Merancang Instrumen Assessment for Learning Berbasis Portofolio Pada Guru-Guru Sekolah. Jurnal Widya Laksana, 10(1), 44. https://doi.org/10.23887/jwl.v10i1.28423.

Pranowo, T. A., \& Prihastanti, A. (2020). Pengaruh Bimbingan Kelompok Melalui Media Audio Visual Terhadap Motivasi Belajar Siswa. Indonesian Journal of Learning Education and Counseling, 2(2), 217-223. https://doi.org/10.31960/ijolec.v2i2.338.

Riswandi. (2018). Kontribusi Iklim Kerja Dan Motivasi Kerja Terhadap Kreatifitas Pamong Belajar Sanggar Kegiatan Belajar (Skb) Di Wilayah Luak Nan Tigo Provinsi Sumatera Barat. Al-Fikrah: Jurnal Manajemen Pendidikan, 5(1), 31. https://doi.org/10.31958/jaf.v5i1.814.

Sarifudin, A. (2019). Peningkatan Kinerja Guru Dalam Implementasi Penilaian Sistem SKS Melalui Supervisi Akademik Pengawas Sekolah. Pendidikan Islam, 08(02), 417-434. https://doi.org/10.30868/ei.v8i2.539.

Siswati, B. H., Hariyadi, S., \& Corebima, A. D. (2017). Pengaruh Model Pembelajaran Rqaad Terhadap Motivasi Belajar dan Keterampilan Metakognitif Mahasiswa Mata Kuliah Strategi Belajar Mengajar Biologi. Jurnal Pendidikan Biologi, 7(2), 108-116. 
https://doi.org/10.17977/um052v12i2p129-135.

Suprihatin, S. (2015). Upaya Guru dalam Meningkatkan Motivasi Belajar Siswa. Jurnal Pendidikan Ekonomi UM Metro, 3(1), 73-82. https://doi.org/10.24127/ja.v3i1.144.

Suryani, N., \& Kholidya, C. F. (2020). Pengembangan Multimedia Berbasis Android Materi Aritmatika Sosial Mata Pelajaran Matematika Dikelas VII MTS Tanada Waru Sidoarjo. Jurnal Mahasiswa Teknologi Pendidikan, 10(29), 1-9. https://jurnalmahasiswa.unesa.ac.id/index.php/jmtp/article/view/36274/32241.

Tambunan, D., \& Nainggolan, E. (2013). Gaya Kepemimpinan Kepala Ruangan dan Produktifitas kerja perawat Pelaksana di Instansi rawat inap RS HKBP Balige. Jurnal Keperawatan HKBP Balige, I(1). http://www.akperhkbp.ac.id/wpcontent/uploads/2013/07/Jurnal-Keperawatan-Akper-HKBP-Balige-Vol-1-No1.pdf\#page $=95$.

Widodo. (2017). Pengelolaan Sanggar Kegiatan Belajar (SKB) pada Era Otonomi Daerah. JPPM (Jurnal Pendidikan Dan Pemberdayaan Masyarakat), 4(2), 113-120. https://journal.uny.ac.id/index.php/jppm/article/view/14869/pdf.

Widodo, W., \& Nusantara, W. (2020). Analysis of Non-formal Education (NFE) Needs in Schools. Journal of Nonformal Education, 6(1), 69-76. https://doi.org/10.15294/jne.v6i1.21568.

Yuangga, K. D., \& Manik, C. D. (2018). Menumbuhkan Motivasi Pendidikan Dan Wirausaha Yang Ramah Lingkungan Untuk Meningkatkan Kesejahteraan Ekonomi Keluarga. Jurnal Pengabdian Dharma Laksana, 1(1), 31-40. https://doi.org/10.32493/j.pdl.v1i1.4535.

Zulfa, M. Y., Daharnis, D., \& Syahniar, S. (2017). Hubungan antara Locus of Control dan Persepsi Siswa tentang Pendidikan dengan Motivasi Belajar serta Implikasinya dalam Pelayanan Bimbingan dan Konseling. JPPI (Jurnal Penelitian Pendidikan Indonesia), 3(1), 1. https://doi.org/10.29210/02017103. 